\title{
Effect of Glass Fibers on the Mechanical and Thermal Conductivity Properties of PP/Alumina Composites
}

\author{
Jianxiang Sun \\ College of Science and Engineering \\ Jinan University \\ Guangzhou 510632, PR China \\ e-mail: 1004079610@qq.com \\ Zhidan Lin \\ College of Science and Engineering \\ Jinan University \\ Guangzhou 510632, PR China \\ e-mail: linzd@jnu.edu.cn
}

\author{
Baofeng Xu \\ College of Science and Engineering \\ Jinan University \\ Guangzhou 510632, PR China \\ e-mail: 670481981@qq.com \\ Jianhua Rong* \\ College of Science and Engineering \\ Jinan University \\ Guangzhou 510632, PR China \\ e-mail: trong@jnu.edu.cn
}

\begin{abstract}
Aluminum oxide (alumina, Al203) and polypropylene (PP) have been often used to produce thermal conductive composites. Short Glass fiber (SGF) is generally used to increase the mechanical properties of materials, but decrease the thermal diffusivity because of its low thermal conductivity. In this work, PP/alumina composites with the addition of short glass fiberwere prepared via melt blending method to obtain thermal conductive materials with enhanced mechanical properties. Crystallization behavior, mechanical and thermal properties of composites and the effects of fibers treatment were investigated. In this article, we use two kinds of alumina particles with different sizes to prepare the PP/alumina composites and discuss the influences of SGF on the structure and properties of the composites. The results show that use of alkaline-treated SGF is better than addition of coupling agents in the PP/alumina composites. Optimum treatment time of SGF was observed as $4 \mathrm{~h}$ when the temperature was $25{ }^{\circ} \mathrm{C}$. Thermal conductivity and mechanical properties of PP/alumina/SGF composites increased further when the SGF was treated.
\end{abstract}

Keywords-alumina; glass fiber; polypropylene; composites; thermal conductivity

\section{INTRODUCTION}

Polypropylene (PP) is one of the most widely used commodity thermoplastic polymers. In addition to good processability character, PP offers excellent thermal stability and chemical resistance. The outstanding characteristics and low price of PP make it widely popular in various applications, including automobile, precision instruments, chemical sector, and aerospace [1]. However, the application of neat PP has been limited to some special fields due to its relatively low thermal conductivity. PP is mostly compounded with other polymers [2,3] or rigid particles [4-9] to overcome this limitation of thermal conductivity for some applications that this character is desirable.
Alumina consists of rigid particles of aluminum oxide that are produced in two forms with sphere and lamellar structures. Alumina powder has low price, great rigidity, good thermal conductivity, and some other useful characters that can modify properties of neat polymers. Alumina composite materials provide good mechanical properties and thermal conductivity. It has attracted great research interest due to its superior performance. We studied the improvement of thermal conductivity of PP composites via mixing different particle size alumina and $\mathrm{PP}$ and examined the crystallization behavior of PP in the presence of alumina particles [10]. Glass fiber is widely used reinforcing filler with a low cost. In previous research, the studies about glass fiber always focus on improving mechanical properties of materials [11-13]. While in thermal conductive materials, people tend to choose carbon fiber [14] to build the heat-conducting network structure because the thermal conductivity of glass fiber is relatively low. To the best of our knowledge, there was no report on the addition of SGF in PP/alumina composites to improve both mechanical and thermal conductivity properties. In this work, we investigated the influences of short glass fiber (SGF) on the structure and properties of PP/alumina. We especially put our efforts on the effects of chemical treatment of SGF on the mechanical and thermal properties of PP/alumina composites.

The aim of this study was to understand the effects of alumina and SGF contents and treatment of SGF on the mechanical and thermal conductivity properties of PP/alumina/SGF composites. In particular, we studied the method and time of the SGF treatment. The study on this subject is very important to find a new low cost method to produce materials with high thermal conductivity. In this work, we examined the influences of treatment method and time of SGF on the thermal conductivity and observed the structures of fibers and composites using SEM technique. 


\section{EXPERIMENTAL METHODS}

\section{A. Materials}

Polypropylene (PP, F401) was obtained from BASF. Alumina was supplied in particles sizes of 1-2 and 50 micrometre by Tansuo Dongguan Technology, PR China. We named the larger particle size alumina as A-alumina and the smaller size as a-alumina. Short glass fibers were obtained from Gaoxian Technology, PR China with the length of $6 \mathrm{~mm}$. The coupling agent KH550 (linear formula $\mathrm{NH}_{2}\left(\mathrm{CH}_{2}\right)_{3} \mathrm{Si}\left(\mathrm{OC}_{2} \mathrm{H}_{5}\right)_{3}$, molecular weight 221.37) was obtained from Tianjin Chemical, PR China.

\section{B. Preparation of PP/alumina/SGF composites}

After adequately drying in a vacuum oven at $80{ }^{\circ} \mathrm{C}$ for $24 \mathrm{~h}, \mathrm{PP}$ and alumina with two different particle sizes and untreated or chemically treated SGF were homogenized and compounded in a twin-screw extruder to obtain PP composites in which the PP/A-alumina/a-alumina was always set at $95 / 2 / 3$. The extrusion temperatures in compounding process were set between 185 and $205{ }^{\circ} \mathrm{C}$ and the screw speed was set at $120 \mathrm{r} / \mathrm{min}$. Table 1 presents the compositions of PP/alumina/SGF composites.

TABLE I. PP/ALUMINA COMPOSITES FILLED WITH UNTREATED SGF AND TREATED SGF WITH DIFFERENT METHODS.

\begin{tabular}{|c|c|c|}
\hline Samples & $\begin{array}{c}\text { Glass fiber } \\
\text { content (wt \%) }\end{array}$ & Treatment \\
\hline 1 & 5 & - \\
\hline 2 & 10 & - \\
\hline 3 & 15 & - \\
\hline 4 & 20 & - \\
\hline 5 & 15 & $\begin{array}{c}\text { Mix with } 1 \% \text { silane coupling agent } \\
\text { KH550 }\end{array}$ \\
\hline 6 & 15 & Steep in $2 \% \mathrm{NaOH}$ solution for $1 \mathrm{~h}$ \\
\hline 7 & 15 & Steep in $2 \% \mathrm{NaOH}$ solution for $2 \mathrm{~h}$ \\
\hline 8 & 15 & Steep in $2 \% \mathrm{NaOH}$ solution for $4 \mathrm{~h}$ \\
\hline 9 & 15 & Steep in $2 \% \mathrm{NaOH}$ solution for $6 \mathrm{~h}$ \\
\hline 10 & 15 & $\begin{array}{l}\text { Mix with 1t\% silane coupling agent } \\
\text { KH550 after steeping in } 2 \mathrm{t} \% \mathrm{NaOH} \\
\text { solution for } 4 \mathrm{~h}\end{array}$ \\
\hline
\end{tabular}

\section{Mechanical properties characterization}

Tensile, flexural, and impact examinations were carried out according to GB standard methods. For each type of composite, five specimens were tested and the average values were reported. Tensile tests were conducted according to GB1040.2 standard method using Type V specimen with a universal testing machine (Zwick/Roell Z005, Zwick Roell Testing Machines) at a crosshead speed of $50 \mathrm{~mm} / \mathrm{min}$. Static flexural examinations were carried out according to GB1042-79 standard method using the same testing machine mentioned above at a crosshead speed of $2 \mathrm{~mm} / \mathrm{min}$. Notched Charpy impact strength tests were performed according to GB1043-79 standard method using a universal impact testing machine (ZBC-50, China Shenzhen SANS Testing Machine). The notches on the specimens were made through gear cutting method.

\section{Microstructures examinations}

The specimens that were broken in the impact examinations were used for morphology studies. The fracture surfaces of the specimens were sputter-coated with gold before conducting microscopic examinations with a
Philips XL-30 environmental scanning electron microscope (ESEM) at an acceleration voltage of $30 \mathrm{kV}$.

\section{E. Thermal conductivity}

Thermal conductivity (TC) of composite materials was examined in temperature range of $30-110{ }^{\circ} \mathrm{C}$ using Netzsch LFA 427 instrument according to laser flash method.

\section{RESULTS AND DISCUSSION}

\section{A. Mechanical properties}

Fig .1 shows the mechanical properties values of PP composites with SGF content in the range of 0-20 wt \%. As the experimental results reveal, when the SGF content increases, the mechanical properties of composites would increase, especially the bending modulus. This observation obviously indicates that SGF play an important role in increasing the mechanical properties of PP composites. When the SGF content was increased to $20 \mathrm{wt} \%$, the bending strength reached to $48.3 \mathrm{MPa}$, which is $40 \%$ increase compared with the neat PP. Whereas, at the same fiber loading the tensile strength increased to $42.2 \mathrm{MPa}$ and the notched impact strength was measured as $40.5 \mathrm{~J} / \mathrm{m}$. However, the tensile strength slightly increased and the impact strength was observed smaller than that of neat PP when the SGF content was at a low level. This observation was due to the presence of alumina in the specimens that decrease the mechanical properties of PP composites, especially the impact strength. The study shows that the decrease of mechanical properties caused by alumina particles can be filled up through addition of SGF. In this study, we observed that SGF was very good reinforcing filler. When the fiber content was $15 \mathrm{wt} \%$, the impact strength reached to $39.1 \mathrm{~J} / \mathrm{m}$ and the tensile strength was up to $38.8 \mathrm{MPa}$. In the following section, we discuss the reinforcing effects of SGF with different chemical treatments.
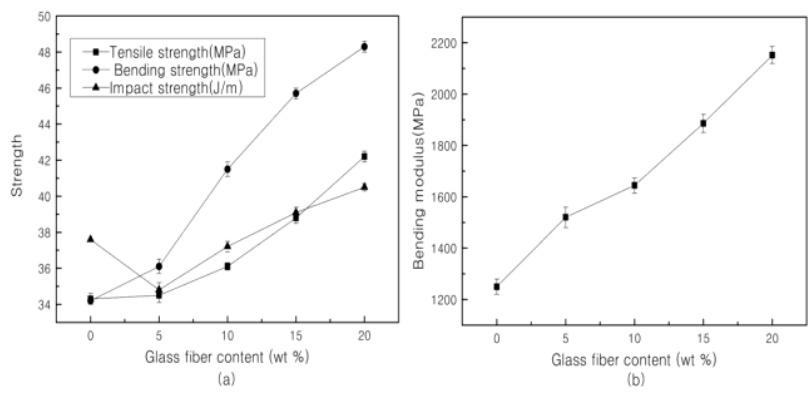

Figure 1. Dependences of (a) strengths and (b) bending modulus on SGF contents.

The variations of mechanical properties of composites filled with treated SGF in different methods are shown in Fig .2. It reveals that in contrast to composites containing untreated SGF, the mechanical properties of composites improved when the SGF was treated with $\mathrm{NaOH}$ solution. The reinforcing efficiency of fibers initially increased and then decreased with increasing the immersion time. The tensile, impact, and bending strengths and the bending modulus were measured as $44.0 \mathrm{MPa}$, 42.5 J/m, 49.7 MPa, and $2237 \mathrm{MPa}$, respectively, which 
were observed as the best mechanical properties when the immersion time in fibers treatment process was $4 \mathrm{~h}$. The mechanical properties of composites filled with SGF treated with silane coupling agent KH550 also showed better performance than those filled with untreated SGF. In the experiments, the tensile, impact, and bending strengths and the bending modulus of composite containing this kind of treated SGF reached to $41.8 \mathrm{MPa}, 41.2 \mathrm{~J} / \mathrm{m}, 49.5 \mathrm{MPa}$, and $2150 \mathrm{MPa}$, respectively. These values are slightly smaller than those of the composite filled with SGF treated with $\mathrm{NaOH}$ solution for $4 \mathrm{~h}$. In this study, we observed that both $\mathrm{NaOH}$ and KH550 treated SGFs are in favor of increasing the mechanical properties of composites. For further studies, we mixed silane coupling agent KH550 with SGF that had been treated with $\mathrm{NaOH}$ solution for $4 \mathrm{~h}$ and then added it to the composite. But, the results did not meet our expectations; the mechanical properties did not show any increase compared with either treatment methods alone; even they declined to the level of untreated SGF reinforced composites.
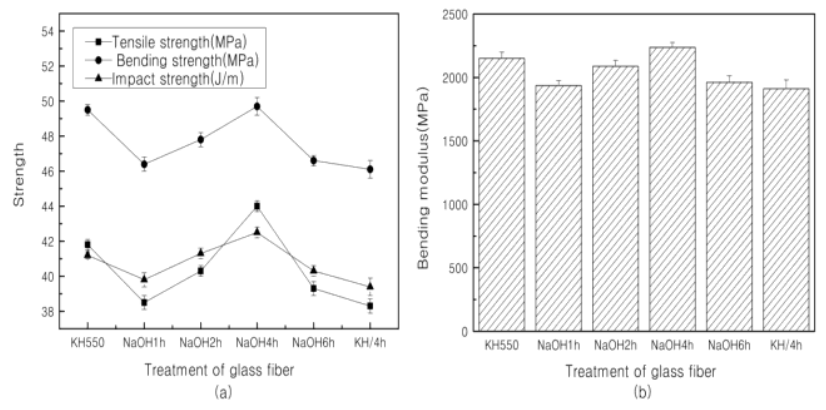

Figure 2. Influence of different treatments of SGF on (a) strengths, and (b) bending modulus.

\section{B. Thermal conductivity observations}

As stated earlier, PP/alumina/SGF composites presented promising mechanical properties. Whether their thermal properties could meet the requirements is unknown. The earlier researches showed that different structures can improve mechanical properties and conductivities of PP composites, but the thermal conductivity of GF is less than that of alumina. The two kinds of alumina and SGF that we used in this work were in different forms, thus, we prepared PP/alumina/SGF composites with a combination of these three kinds of additives to study the thermal properties and structures. The preparation method was the same as the process we used for production of PP/alumina samples. Fig .2 presents the results of thermal conductivity examinations of PP composites with various compositions. Because the composite containing 2\% A-alumina and 3\% a-alumina revealed the best conductivity of greater than $0.3 \mathrm{~W} / \mathrm{mK}$, we selected PP/A-alumina2/a-alumina3 composition for further examinations and modification. We added some amounts of neat or treated SGF to observe their effects on thermal properties. Data in Fig .2 for PP/A-alumina/SGF composite indicate the achievement of excellent thermal conductivity. The thermal conductivity could be improved by nearly $20 \%$ to $0.42 \mathrm{~W} / \mathrm{mK}$ even when the SGF was not treated. We observed that alkali treatment results in better fibers than treatment with coupling agent in both mechanical and thermal properties of manufactured composites. Thermal conductivity could still improve by $15 \%$ after the SGF was under the alkali treatment. The SEM micrographs reveal that the alumina can more easily attach to the alkali-treated SGF. But, coupling agenttreated SGF combined PP tighter so that the alumina particles could not easily attach to SGF surface. These improvements in mechanical and thermal properties were also due to the facts that alkali-treated fibers were dispersed more evenly in the PP matrix, which was indicated by SEM observations. Therefore, the heatconducting network structure can be constructed well.
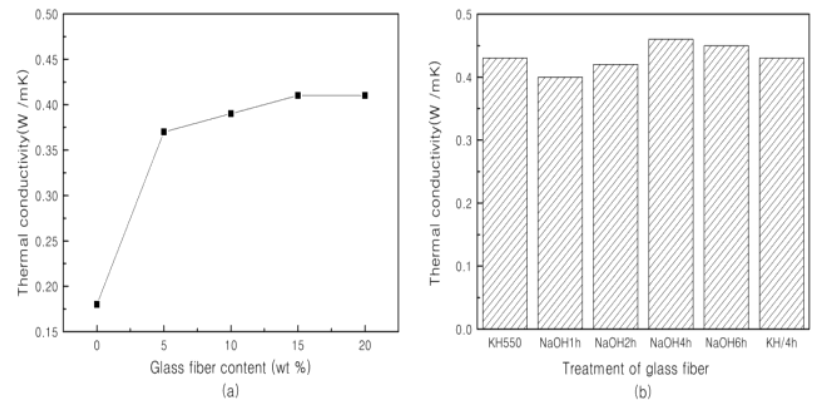

Figure 3. Dependences of thermal conductivity of different samples with: (a) various glass fibers contents, (b) various surface treatments.

Moreover, we studied the influence of treatment time of SGF. The results showed that the optimum treatment time was $4 \mathrm{~h}$ at $25{ }^{\circ} \mathrm{C}$. When the fibers were treated for longer times, the form of glass fiber was altered, leading to the failure of heat-conducting network structure. The resulting mechanical and thermal conductivity properties approve this discussion. However, when SGF was mixed with $1 \mathrm{wt} \%$ silane coupling agent KH550 after steeping in $2 \% \mathrm{NaOH}$ solution for $4 \mathrm{~h}$, the mechanical and thermal properties decreased.

\section{Microstructural analysis}
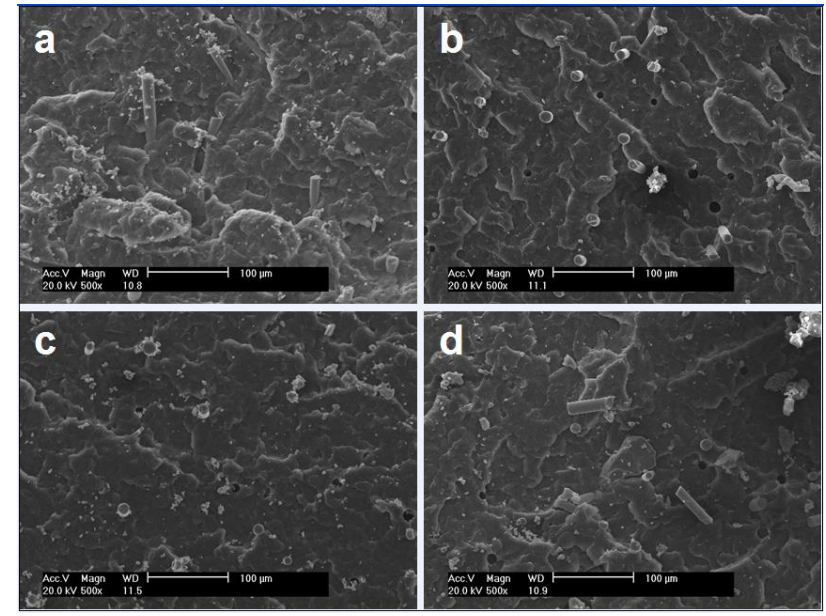

Figure 4. SEM micrographs of the impact fracture surfaces of composites filled with $15 \%$ SGF with different treatments: (a)neat SGF (b) Mix with $1 \%$ silane coupling agent $\mathrm{KH} 550$, (c) steep in $2 \% \mathrm{NaOH}$ solution for $4 \mathrm{~h}$, (d) mix with $1 \mathrm{t} \%$ silane coupling agent KH550 after steeping in $2 \mathrm{t} \% \mathrm{NaOH}$ solution for $4 \mathrm{~h}$.

Fig 4 shows the SEM micrographs of impact fracture surfaces of composites samples. Compared with KH550 or $\mathrm{NaOH}$ treated SGF reinforced PP/alumina composites, 
there were larger numbers of untreated fibers that were pulled out from the PP matrix, indicating that there were less surface contact and weaker bonding between untreated fibers and PP. We also observed that fibers treated with silane were partially pulled out of the matrix, whereas alkali treated ones were hardly pulled out. This observation indicates that $\mathrm{NaOH}$ treatment makes better bonding and mechanical properties, as mentioned above. From Fig .4(c), we can find that some alumina particles form a network of PP-alumina- fibers, leading to a better heat-conduction compared with untreated reinforced PP/alumina. Fig .4(d) shows less glass fiber debris compared with micrographs in Fig .4(b) and (c). In order to find out the reason behind decrease of some of the properties, the differences in microstructures of fibers were analyzed using SEM micrographs (Fig .5).
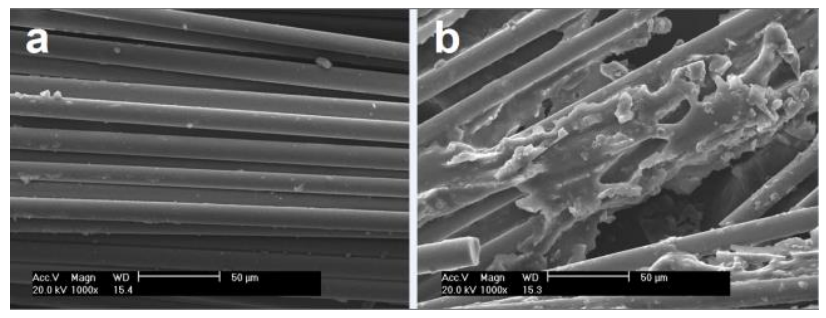

Figure 5. SEM micrographs of SGF: (a) untreated glass fiber, (b) glass fiber treated with $\mathrm{NaOH}$ solution and KH550.

The micrograph in Fig .5(a) clearly shows the morphology of the untreated glass fibers as a separate bundle of fibers. In contrast, the SGF treated with $\mathrm{NaOH}$ and KH550 lost its original cylindrical shape in some areas and showed a kind of fibers-glued morphology in which fibers are stuck together with incomplete glass fiber around them. Thus, only the remaining fibers fragments really play a role in enhancement of the PP/alumina composite in sample 10. The mechanical properties of sample 10 were observed as low as that of the untreated SGF reinforced composite.

\section{Crystallization behavior of PP in composites}

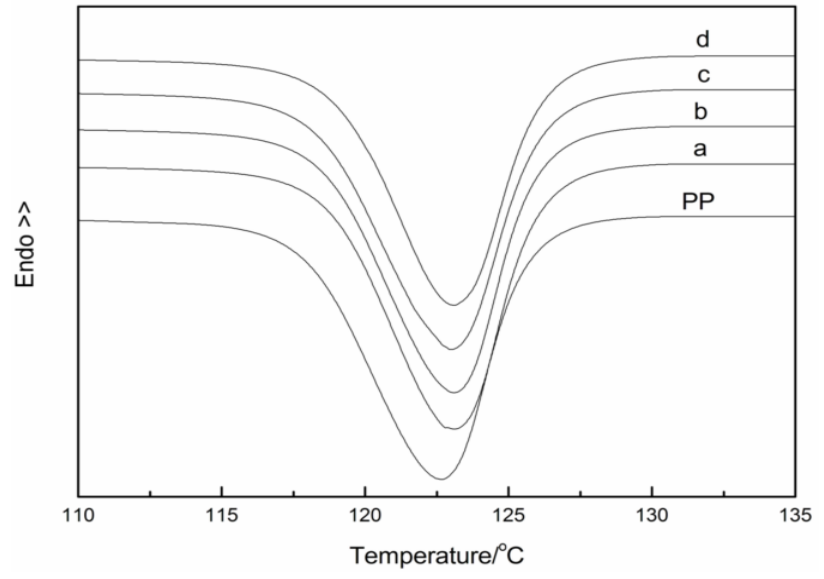

Figure 6. DSC thermograms of neat $\mathrm{PP}$ and $\mathrm{PP} /$ alumina filled with $15 \%$ SGF with different treatments: (a)neat SGF, (b) Mix with $1 \%$ silane coupling agent $\mathrm{KH} 550$, (c) steep in $2 \% \mathrm{NaOH}$ solution for $4 \mathrm{~h}$, (d) mix with $1 \mathrm{t} \%$ silane coupling agent $\mathrm{KH} 550$ after steeping in $2 \mathrm{t} \% \mathrm{NaOH}$ solution for $4 \mathrm{~h}$.
Generally speaking, the higher the degree of crystallinity, the less amorphous region available to contribute in the elastic character of the polymer at room temperature ( $\mathrm{Tg}$ of amorphous phase of $\mathrm{PP}$ is approximately $\left.-20{ }^{\circ} \mathrm{C}\right)$. Therefore, the higher degree of crystallinity results in smaller impact strength of PP, whereas the tensile and bending strengths increase. Some typical DSC samples were analyzed to find out whether the addition of SGF changes the crystallinity of PP/ alumina composite (See Fig .6). In contrast to neat PP, the crystallization peak of samples containing $15 \mathrm{wt} \% \mathrm{SGF}$ slightly shifted toward the right, which was so insignificant that we can consider it almost as no change. In other word, the addition of SGF does not significantly affect the crystallinity of PP.

\section{CONCLUSIONS}

In this paper, we studied the effects of SGF on the mechanical properties, thermal conductivity, and crystallization behavior of PP/alumina composites. The results show that the addition of SGF with different treatments to PP makes it more conducive and improves the comprehensive performance of polymer. When the total amount of alkali-treated SGF in the composite was 15 wt $\%$, it exhibited a better overall performance. Thermal conductivity increased by almost $40 \%$ compared with the composite filled with alumina (we studied PP/alumina composites before). The shape of the filler also affects the properties of the composites. A combination of fillers with different shapes was observed to be more effective for improvement of thermal conductivity. Moreover, different kinds of treatment and its process time of SGF affect the mechanical and thermal properties of PP composites Alkali-treated fibers revealed better performance than those treated with coupling agent. The optimum alkali treatment time was found as $4 \mathrm{~h}$. The observations made in this study are significant for those composites containing fillers with different shapes and treated in various methods.

\section{ACKNOWLEDGMENT}

This project was supported by National Students' Innovation and Entrepreneurship Training Program(Grant No. 201410559043)

\section{REFERENCES}

[1] J. Karger-Kocsis, "Polypropylene Structure, Blends and Composites," Springer, Berlin, 1994.

[2] C. K. Kum, Y.-T. Sung, Y. S. Kim, H. G. Lee and W. N. Kim, "Effects of Compatibilizer on Mechanical, Morphological, and Rheological Properties of Polypropy-lene/-poly(acrylonitrilebutadiene-styrene) Blends," Macromolecular Research, Vol. 15, 2007, pp. 308-314.

[3] A. K. Dhibar, J. K. Kim and B. B. Khatua, "Cocontinuous Phase Morphology of Asymmetric Compositions of Polypropylene/High-Density Polyethylene Blend by the Addition of Clay," Journal of Applied Polymer Science, Vol. 119, 2011, pp. 3080-3092.

[4] Y. W. Leong, M. B. A. Bakar, Z. A. M. Ishak, A. Ariffin and B. Pukanszky, "Comparison of the Mechanical Properties and Interfacial Interactions between Talc, Kaolin, and Calcium Carbonate Filled Polypropylene Composites," Journal of Applied Polymer Science, Vol. 91, No. 5, 2004, pp. 3315-3326, doi:10.1002/app.13542 
[5] E. Sancaktar and E. Walker, "Effects of Calcium Carbonate, Talc, Mica, and Glass-Fiber Fillers on the Ultrasonic Weld Strength of Polypropylene," Journal of Applied Polymer Science, Vol. 94, No. 5, 2004, pp. 19861998, doi:10.1002/app.21102

[6] M. Tajvidi1, R. H. Falk and J. C. Hermanson, "Effect of Natural Fibers on Thermal and Mechanical Properties of Natural Fiber Polypropylene Composites Studied by Dynamic Mechanical Analysis," Journal of Applied Polymer Science, Vol. 101, No. 6, 2006, pp. 4341-4349, doi:10.1002/app.24289

[7] J. Mirbagheri, M. Tajvidi, J. C. Hermanson and I. Ghasemi, "Tensile Properties of Wood Flour/Kenaf Fibre Polypropylene Hybrid Composites," Journal of Applied Polymer Science, Vol.105, No. 5, 2007, pp. 3054-3059, doi:10.1002/app.26363

[8] A. K. Bledzki and O. Farukh, "Wood Fibre Reinforced Polypropylene Composites: Effect of Fibre Geometry and Coupling Agent on Physico-Mechanical Properties," Applied Composite Materials, Vol. 10, No. 6, 2003, pp. 365-379, doi:10.1023/A:1025741100628

[9] A. K. Bledzki, A. A. Mamuna and J. Volk, "Physical, Chemical and Surface Properties of Wheat Husk, Rye Husk and Soft Wood and Their Polypropylene Composites," Composites Part A, Vol. 41, 2010, pp. 480-488, doi:10.1016/j.compositesa.2009.12.004
[10] B. F. Xu, Z. D. Lin, C. M. Du, H. B. Lin, and K.Y. Liang, "Mechanical Properties, Morphology, and Thermal Conductivity of Polyamide Composites Filled with Graphene Nanoplatelets, $\mathrm{Al}_{2} \mathrm{O}_{3}$ and graphite," Materials Research Innovations, in press, doi:10.1179/1432891715Z.0000000001576

[11] R. Mangire, "Micro-macro Mechanical Behavior of FiberReinforced Pultruded Composite Gratings," M.E.S. Thesis, Lamar University, Beaumont, 1999.

[12] H. Q. Xie, S. Zhang and D. Xie, "An Efficient Way to Improve the Mechanical Properties of Polypropylene/Short Glass Fiber Composites," Journal of Applied Polymer Science, Vol. 96, No. 4 2005, pp. 1414-1420, doi:10.1002/app.21575

[13] M. T. Run, H. Z. Song, Y. P. Hao, X. M. Hu and C. G. Yao, "Preparation, Structure, and Properties of the PT- T/SGF Composites," Polymer Composites, Vol. 30, No. 6, 2008, pp. 776781, doi: $10.1002 / \mathrm{pc} .20617$

[14] E. H. Weber, M. L. Clingerman, and J. A. King, "Thermally Conductive Nylon 6,6 and Polycarbonate Based Resins. I Synergistec Effects of Carbon Fillers," Journal of Applied Polymer Science, Vol. 88, No. 1, 2003, pp. 112-122, doi:10.1002/app.11571. 